\title{
PERCURSOS E DESAFIOS AO LONGO DO PROCESSO DE CONSOLIDAÇÃO DO PORTUGUÊS PARA ESTRANGEIROS NA UFV
}

\author{
RUTAS Y RETOS A LO LARGO DEL PROCESO DE CONSOLIDACIÓN DEL \\ PORTUGUÉS PARA EXTRANJEROS EN LA UFV
}

\section{PATHS AND CHALLENGES THROUGHOUT THE CONSOLIDATION PROCESS OF THE PORTUGUESE FOR FOREIGNERS AT UFV}

\author{
Idalena Oliveira CHAVES ${ }^{1}$ \\ Glauber HEITOR-SAMPAIO ${ }^{2}$
}

RESUMO: Este artigo tem por objetivo apresentar o percurso histórico do ensinoaprendizagem do Português como Língua Estrangeira (PLE) na Universidade Federal de Viçosa (UFV). Por conseguinte, propõe-se a descrever brevemente as ações pertinentes ao processo de internacionalização da instituição que têm influído para a discussão e consolidação de iniciativas políticas de formação de professores de PLE desde 2015. A partir da consolidação recente da área, sustentada pelos pilares categorizados neste artigo como ensino, pesquisa e extensão, levantam-se também alguns pontos sobre a situação atual da área no referido cenário, culminando na exposição de ações políticas necessárias para a formação docente, propostas pelo Departamento de Letras da instituição.

PALAVRAS-CHAVE: Português para estrangeiros. Ensino. Pesquisa. Extensão. Formação de professores.

RESUMEN: Este artículo presenta el desarrollo histórico de enseñanza-aprendizaje del Portugués Lengua Extranjera (PLE) en la Universidad Federal de Viçosa (UFV). Por lo tanto, se describe brevemente las acciones implementadas por la institución hacia su proceso de internalización con el fin de destacar cómo han sido partícipes de la discusión y fortalecimiento de medidas políticas para la formación de profesores desde 2015. Basándose en la reciente consolidación del campo y potenciando la legitimad de los pilares categorizados como enseñanza, investigación y extensión universitaria, plantease algunos puntos en lo que respecta al ámbito del portugués para extranjeros en este escenario, incluyendo con la exposición de acciones que señalan la importancia de políticas de formación docente más vigorosas como recientemente expuso por el Departamento de Lenguas de la institución.

PALABRAS CLAVE: Portugués para extranjeros. Educación. Investigación. Extensión universitaria. Formación del profesorado.

\footnotetext{
${ }^{1}$ Universidade Federal de Viçosa (UFV), Viçosa - MG - Bra sil. Docente do Departamento de Letras. Doutorado em Letras (UFMG). ORCID: https://orcid.org/0000-0002-2921-6425.E-mail: idalena@ufv.br

2 Instituto Federal de Minas Gerais (IFMG), Congonhas - MG - Brasil. Docente do Departamento de Linguagens e Códigos. Doutorando em Linguística Aplicada (UNICAMP). ORCID: https://orcid.org/0000-00023636-7643.E-mail: glauber.sampaio@ifmg.edu.br
} 
ABSTRACT: This article aims to present the historical development of teaching and learning Portuguese as a Foreign Language (PFL) at Viçosa Federal University (UFV). To that end, we bring a slight description of some actions implemented at the institution towards its internalization process and how they have partaken in the discussion and strengthening of policy ventures in teacher education since 2015. Based on the recent consolidation of the field and grounded on the legitimation of the pillars categorized as teaching, research, and extension, some points about the state of the Portuguese for foreigners in this scenario are raised, culminating in the exposure of some politic al actions which point out the need of farther teacher training policies as recently proposed by the Languages Department.

KEYWORDS: Portuguese for foreigners. Education. Research. Extension. Teacher education.

\section{Introdução}

Falar português na atualidade é altamente recomendado para todos aqueles que desejam estudar ou trabalhar no Brasil. O português é, indiscutivelmente, uma língua internacional e faz parte de dois grandes blocos político-econômicos: a União Europeia (oficialmente declarada língua internacional junto ao francês, o inglês e o espanhol) e o Mercosul, possuindo status de língua oficial juntamente ao espanhol.

Segundo o Blogue do Instituto Internacional da Língua Portuguesa (IILP) (2019 [Web]),

[...] a nossa língua é uma das 10 línguas mais importantes do mundo e o Brasil é o principal motivo para o aumento do número de alunos de português no ensino superior norte-americano, que cresceu 10,1 por cento entre 2009 e 2013 e tornou-se a terceira língua com maior crescimento nos Estados Unidos.

Isso se reflete na procura por cursos de português que vêm aumentando nos últimos anos em várias instituições no Brasil e no exterior. De acordo com o Portal $\mathrm{ECB}^{3}$, a "Rede Brasil $\mathrm{Cultural}^{4}$, instrumento do Itamaraty para a promoção da língua portuguesa e da cultura brasileira no exterior, atende a 9 mil alunos em 44 países, de cinco continentes, com cerca de 200 professores". Através de programas como o Leitorado ${ }^{5}$, universidades de renome internacional como Harvard (Estados Unidos), Fudan (China), Sorbonne (França), King's College (Reino Unido) e Colônia (Alemanha), além de várias outras situadas em todos os

${ }^{3}$ Disponível em: http://www.ebc.com.br/noticias/internacional/2015/05/cresce-procura-pelo-ensino-doportugues-do-brasil-no-mundo. Acesso em: 08 mar. 2021.

${ }^{4}$ Disponível em: http://redebra silcultural.ita maraty.gov.br/en/. Acesso em: 08 mar. 2021.

${ }^{5}$ Disponível em: https://wwwl.capes.gov.br/bolsas-e-auxilios-internaciona is/pais/218-multina cional/10088programa-leitora do. Acesso em: 07 mar. 2021. 
continentes, têm promovido cursos de língua e cultura brasileira através de parcerias governamentais.

Em vários países, como Coreia do Sul, China, Japão, Estados Unidos, dentre outros, é comum a presença de um professor especialista na área de ensino de português, integrado ao corpo docente dos Departamentos de Linguagem de suas universidades. Contudo, no Brasil, a contrapartida de atendimento a uma demanda específica de profissionais voltados ao ensino da língua em contexto de imersão é ainda recente.

Embora já houvesse iniciativas de ensino de português para estrangeiros no país desde a década de 50, como aponta Almeida Filho (2012) ao citar um manual didático sobre o ensino de português para estrangeiros, criado pela professora Mercedes Marchand, no Rio Grande do Sul em 1957, não havia referência científica a nenhum esforço ou legitimidade brasileira em termos de pesquisas e confecções de métodos e materiais didáticos para o ensino de português para tal público. O florescimento dos estudos e publicações, e o crescimento de cursos especializados, notadamente nos Estad os Unidos, cresceram sensivelmente nas décad as de 60 e 70 (ALMEIDA FILHO, 1992). Ao mesmo tempo, as universidades brasileiras iniciaram uma corrente de tentativas de institucionalização dos cursos para estrangeiros em ambientes universitários, bem como a implementação de especializações para professores na área, até então totalmente nula, principalmente em termos de treinamento no nível de pósgraduação. Como pontua Almeida Filho (1992), não é fácil definir com precisão o pioneirismo das universidades brasileiras sobre a implantação de cursos de Português para Estrangeiros (doravante, PLE). Entretanto, com respeito ao desenvolvimento de pesquisas e formação de professores da área, a Universidade Estadual de Campinas (Unicamp) se destaca desde 1976.

Todavia, esse despertar no Brasil só ocorreu na década de 80 , quando começaram a surgir os primeiros livros didáticos produzidos nacionalmente. Somente depois da década de 90 que as universidades brasileiras iniciaram o movimento de ensino de PLE. Dentre elas, destacaram-se as Federais do Rio Grande do Sul (UFRGS), do Rio de Janeiro (UFRJ), de Minas Gerais (UFMG), de Santa Catarina (UFSC), de Juiz de Fora (UFJF), a Universidade de São Paulo (USP), de Brasília (UnB), a Estadual de Campinas (Unicamp), as Católicas do Rio de Janeiro (PUC-Rio) e Rio Grande do Sul (PUC-RS), sendo que somente a Unicamp, a UFRJ e a UnB ofereciam cursos regulares e constantes de catálogo com docentes/pesquisadores plenamente enquadrados na carreira docente (ALMEIDA FILHO, 1992). Os cursos de PLE eram oferecidos na modalidade de extensão universitária, a exemplo do Programa de Ensino de Língua Portuguesa para Estrangeiros criado pela professora Regina 
Lúcia Perét Dell'Isola no Centro de Extensão da Faculdade de Letras da UFMG (CenexFALE) ${ }^{6}$, e o Programa de Português para Estrangeiros (PPE) pela professora Margarete Schlatter, na Universidade Federal do Rio Grande do Sul (UFRGS), ambos em 1993.

Acompanhando o fluxo de deslocamento migratório internacional para o Brasil e as necessidades de ensino da língua nacional para estrangeiros, a Universidade Federal de Viçosa (UFV) também propiciou iniciativas e propostas para o ensino de PLE, como descrito a seguir.

\section{Um brevíssimo histórico do processo de internacionalização na UFV}

A mobilidade no campo educacional não é um processo recente e data desde os séculos XVII e XVIII com o chamado "Grand Tour"7, em que jovens europeus da aristocracia viajavam acompanhados de um professor particular no intuito de visitar o mundo clássico para buscar conhecimento e aprender línguas. O que antes era dado às elites foi, aos poucos, se democratizando. Nos anos 1990, com a assinatura da Declaração de Bolonha ${ }^{8}$ (BASTOS, 2008), a mobilidade se intensificou nas universidades europeias, unificando o ensino superior.

As discussões sobre mobilidade internacional e internacionalização das Instituições de Ensino Superior (IES) ${ }^{9}$ brasileiras só emergem dez anos mais tarde em relação ao contexto europeu e fazem parte do contexto político da primeira década dos anos 2000. A partir de então, os programas de apoio a pesquisa e ao intercâmbio de conhecimento começaram a ser ampliados, tendo como grandes colaboradores os órgãos de fomento nacionais em cooperação com organizações estrangeiras. Em 2009, por exemplo, cerca de 2.000 bolsas da Capes e do CNPq foram destinadas a estrangeiros através dos programas de Pós-Graduação (PEC-PG) e graduação (PEC-G) ${ }^{10}$. Houve, então, a ampliação de concessões de projetos de pesquisa por cooperativados e associações internacionais envolvendo consultorias para universidades estrangeiras e outras instituições, como relatado em Morosini (2006). De acordo com dados

${ }^{6}$ Consultar Diniz e Dell'isola (2020).

${ }^{7}$ Consultar Bertrand (2013).

8 A Declaração de Bolonha é um documento conjunto assinado pelos Ministros da Educação de 29 países europeus, reunidos na cidade italiana de Bolonha em 1999. Disponível em: http://www.magnacharta.org/resources/files/BOLOGNA_DECLARATION.pdf. Acesso em: 16 mar. 2021.

9 Bartell (2003), citado por Morosoni (2006), "conceitua a Internacionalização como trocas internacionais relacionadas à educação e a Globalização como uma avançada fase no processo que envolve a internacionalização" (p. 115).

${ }^{10}$ PEC-G (Programa de Estudante-Convênio de Graduação) e PEC-PG (Programa de Estudante-Convênio de Pós-Graduação) são atividades de cooperação entre o Brasil e países em desenvolvimento, cujo objetivo é a formação de recursos humanos, para possibilitar aos cidadãos desses países com os quais o Brasil mantém acordos educacionais ou cultura is realização de estudos universitários nas Instituições de Ensino Superior (IES) brasileiras participantes convênio. Para informações adicionais sobre os programas. Disponível em: http://portal.mec.gov.br/pec-g?ativo=531. Acesso em: 07 dez. 2015. 
do $\mathrm{CNPq}^{11}$, hoje são 59 os países participantes no PEC-G, sendo 25 da África, 25 das Américas e 9 da Ásia, dentre os quais a UFV se destacou como receptora ao acolher estudantes de mobilidade advindos de países africanos e de universidades hispanoamericanas.

Nesse panorama, a língua portuguesa passa a ser parte desse processo, compondo a pauta de discussões relacionadas às ações políticas implementadas em todas as áreas do conhecimento. Em uma perspectiva macro, as instituições brasileiras se deparam com o movimento intenso de professores visitantes e estudantes internacionais conveniados, com ações tais quais a certificação de proficiência em português (o CELPE-Bras) e a criação de programas como o Ciências Sem Fronteiras, em 2011 e o Idiomas Sem fronteiras (ISF) no ano seguinte. A UFV acompanhou também estes fluxos e deslocamentos.

Portanto, a cooperação internacional e a mobilidade acadêmica são processos basilares que sustentam e acompanham o longo histórico de desenvolvimento e institucionalização da UFV. Desde a sua concepção, a instituição recebe, viabiliza e executa múltiplos projetos, frutos de acordos internacionais através dos quais é possível ponderar que o seu processo de internacionalização se iniciou paralelamente a sua idealização.

Derivada da antiga Escola Superior de Agricultura e Veterinária (ESAV), inaugurada em 1926 e projetada nos moldes dos Landgrant Colleges, escolas superiores agrícolas criadas nos Estados Unidos no final do século XIX (RIBEIRO, 2009), a UFV federalizou-se em 1969 após um período de desenvolvimento sólido como Universidade Rural do Estado de Minas Gerais (UREMG, 1948-1969). Logo cedo, seu funcionamento contou com a cooperação bilateral entre Brasil e Estados Unidos, especificamente por meio da direção de Peter Henry Rolfs, professor estadunidense contratado à época segundo acordo estabelecido entre o governo do estado de Minas Gerais e os Estados Unidos (RIBEIRO, 2006). Conforme Baêta (2016), mais da metade do corpo docente da instituição na década de 1930 era composto por professores advindos dos Estados Unidos, da Alemanha, da Rússia e da Dinamarca.

Embora a instituição tenha passado por problemas de ordem política durante seus primeiros anos, sua transformação em UREMG, em 1948, coincidiu com o convênio de assistência técnica firmado entre o governo mineiro e a American International Association for Economic and Social Development (AIA). A iniciativa foi garantida, posteriormente, pela cooperação da Purdue University em acordo consolidado entre o Ministério das Relações Exteriores do Brasil e a embaixada dos Estados Unidos por intermédio do Institute of Inter-

${ }^{11}$ Disponível em: http://www.dce.mre.gov.br/PEC/G/historico/introducao.php. Acesso em: 08 mar. 2021. 
American Affairs (IIAA), considerada precursora da internacionalização da educação superior no estado de Minas Gerais (RIBEIRO, 2009).

As ações de cooperação internacional, assim como a própria ideologia de cooperação técnica no campo da produção agrária que impulsionou a sua criação, estimularam o intercâmbio de professores e, a posteriori, de pesquisadores e estudantes estrangeiros, movimentos estes que podem ser considerados parte das forças propulsoras que alavancaram a abertura da organização para a constante expansão de atividades de colaboração técnicoeducacionais e culturais entre professores, pesquisadores e estudantes em esfera internacional. Estes movimentos posicionaram inevitavelmente a UFV no rol das discussões contemporâneas sobre a internacionalização das IES brasileiras.

Atualmente, a universidade conta com diversos contratos, acordos e convênios firmados com embaixadas de múltiplos países em mais de cem universidades no exterior. Estudantes de várias nações podem realizar estágios acadêmicos e ingressar em cursos de graduação ou pós-graduação. Esse contingente de estudantes e pesquisadores internacionais é descrito por Baêta ao indicar que

a UFV [está] entre as cinco universidades com o maior percentual de estudantes estrangeiros no país e, dentre as IFES brasileiras, é a segunda com um total de $3 \%$ contra $4 \%$ da UFSC. Em termos proporcionais, tem o triplo de estudantes estrangeiros quando comparada à maior IFES de Minas Gerais, a UFMG, segundo dados da Times High Education (2016). Nesses indicadores, há $4 \%$ a $5 \%$ de presença discente estrangeira entre as estaduais paulistas USP, UNESP e UNICAMP, tidas como referências no país nos rankings internacionais, porém distantes de universidades alemãs e holandesas, com a média de $20 \%$, e das canadenses e estadunidenses, com até $50 \%$ de estudantes estrangeiros (BAÊTA, 2016, p. 222).

O contingente de estudantes em mobilidade acadêmica na instituição continua a ser significativo. Conforme dados do Relatório Anual da DRI/UFV ${ }^{12}$, a instituição recebeu em 2019 mais de 300 estudantes internacionais, alocados em diversos programas de graduação e pós-graduação em seus 38 departamentos vinculados a quatro Centros de Ciências (AgráriasCCA; Biológicas e da Saúde-CCB; Exatas e Tecnológicas-CCE; e Humanas, Letras e Artes$\mathrm{CCH}$ ). Excetuando-se professores visitantes na instituição, de um total de 940 professores efetivos, 27 são estrangeiros, o que corresponde a 2,53\% do corpo docente, distribuídos conforme o quadro abaixo:

12 Disponível em: https:/www.dri.ufv.br/wp-content/uploads/Relat\%C3\%B3rio-2019.pdf. Acesso em: 15 abr. 2020. 
Tabela 1 - Presença de professores estrangeiros na UFV

\begin{tabular}{|l|c|c|c|}
\hline PAíS & CENTRO & $\mathbf{N}^{\mathbf{0}}$ POR DEPARTAMENTO & TOTAL \\
\hline Argentina & $\mathrm{CCB} / \mathrm{CCH}$ & 02 & 02 \\
\hline Colômbia & $\mathrm{CCA} / \mathrm{CCE} / \mathrm{CCH}$ & $02 / 02 / 01$ & 05 \\
\hline Cuba & $\mathrm{CCE}$ & 01 & 01 \\
\hline Espanha & $\mathrm{CCH}$ & 01 & 01 \\
\hline Estados Unidos & $\mathrm{CCE}$ & 01 & 01 \\
\hline Índia & $\mathrm{CCE}$ & $01 / 01$ & 02 \\
\hline Irã & $\mathrm{CAF} / \mathrm{CCE}$ & 01 & 01 \\
\hline Noruega & $\mathrm{CCA}$ & 01 & 01 \\
\hline Paraguai & $\mathrm{CCE}$ & $06 / 02$ & 08 \\
\hline Peru & $\mathrm{CCE} / \mathrm{CAF}$ & 01 & 01 \\
\hline Uruguai & $\mathrm{CCH}$ & $02 / 01$ & 03 \\
\hline Naturalizados & $\mathrm{CCB} / \mathrm{CCE}$ & & 0 \\
\hline TOTAL 27 & & & 0 \\
\hline
\end{tabular}

Fonte: Acervo dos autores

Embora as parcerias entre Brasil e Estados Unidos tenham iniciado as relações internacionais na instituição, principalmente baseadas pelo objetivo estratégico da América do Norte em consolidar sua hegemonia econômica no sul global no período pós-guerra, a UFV estabeleceu, ao longo dos anos, importantes acordos com outros países vizinhos.

Com a formação do Mercado Comum do Sul (MERCOSUL) em 1991, o panorama de fluxo migratório para o Brasil se modificou. Os países integrantes do bloco incluíram em agenda discussões sobre uma série de questões, dentre as quais destacou-se a educação, aspecto de ampla relevância para que se efetivasse o estreitamento das relações dos países membros da comunidade (FULQUET, 2006). Conforme salienta Fulquet, o debate acerca da internacionalização do ensino superior já estava aquecido enquanto o projeto nomeado Setor Educacional do MERCOSUL (SEM) buscava se "firmar como um instrumento de construção de novos espaços de desenvolvimento econômico, político e cultural” (FULQUET, 2006, p. 8) para criar sua identidade regional.

A partir de então, houve um crescente interesse na aprendizagem do português por estudantes de vários países da América Latina que começavam a perceber o Brasil como possibilidade de acesso à educação superior. Estes dados são relevantes para sistematizarmos o trajeto percorrido pela mobilidade acadêmica internacional no cenário da UFV e como tal fator estimulou a criação da área de português para estrangeiros, conforme abordaremos a seguir. 


\section{O processo histórico de consolidação da área de PLE/UFV}

No contexto institucional do qual trata este artigo, a Diretoria de Relações Internacionais e Interinstitucionais (DRI-UFV), existente desde a década de 70 sob a chancela de Assessoria Internacional e de Parcerias, promovida a diretoria em 2010, contribuiu enormemente para os processos de internacionalização e institucionalização da área do PLE, o que não significa que já não houvesse na instituição ofertas de cursos de português para os estudantes intercambistas, os quais categorizaremos a seguir em estágios e propósitos específicos.

\section{Estágio de desenvolvimento pré-consolidação do PLE/UFV}

Sobre o tema ensino de PLE na UFV, Baêta (2016) assinala que não havia na instituição registros anteriores a 2005 de cursos de português para estrangeiros, sendo que a oferta regular somente teve início a partir de então. Segundo relatos apresentados em sua tese de doutoramento (op. cit. p. 247), aprender o português oficialmente parecia não ter relevância naquela época para o contexto diplomático da instituição. Os estrangeiros que lá chegavam, "se viravam", aprendiam informalmente ou se comunicavam com a ajuda de intérpretes, pois o primordial era integrá-los de forma diplomática para que tivessem uma boa recepção e estadia na universidade e na cidade. Contudo, emergiu um tipo de ensino informal, em que professores auxiliavam os alunos estrangeiros e promoviam um sistema de Tanden $^{13}$, método de aprendizado autônomo de língua estrangeira baseado na troca linguística entre falantes nativos das duas línguas, interessados em aprender a língua do par. Como afirma Santos (2009), “a participação num tanden não exige uma formação prévia como professor da língua que se vai ensinar: o simples fato de ser seu usuário (nativo ou competente) é suficiente [...]" (SANTOS, 2009, p. 149).

Paulatinamente, as aulas começaram a ser ministradas por professores do Departamento de Letras e, principalmente, a partir de 2005, por estagiários do CELIN (Curso de Extensão em Língua Inglesa), alunos da licenciatura em Letras Português-Inglês em seus anos finais do curso. Em particular, a oferta era realizada por graduandos em Letras que voltavam do intercâmbio acadêmico nos Estados Unidos promovido pelo convênio CapesFipse (Programa de Consórcios em Educação Superior entre Brasil e Estados Unidos). À época, inclusive, as aulas de PLE eram estritamente direcionadas aos intercambistas

${ }^{13}$ Disponível em: https://www.unibe.ch/studies/degree_programs/language_courses/aes/tandem/index_eng.htm1. Acesso em: 16 fev. 2021. 
estadunidenses participantes do convênio citado. O curso era realizado de forma intensiva e anualmente (cursos de verão durante os meses de janeiro e fevereiro), antecedendo o início do calendário acadêmico, com o objetivo de ambientar e fornecer aos alunos a prática com a língua para que cursassem disciplinas de graduação por um ou dois semestres letivos.

Os cursos eram planejados no intuito de que o estudante recém-chegado à cidade tivesse total imersão na língua e cultura. Cada curso era oferecido por três professores em formação (estagiários) e dividido entre habilidades (um deles trabalhava com a prática de conversação, outro com a leitura e escrita e outro focalizava aspectos da estrutura da língua). Vale ressaltar que os estagiários não possuíam nenhum tipo de formação específica para o ensino de PLE e todo o material desenvolvido para o curso, bem como as metodologias utilizadas, partiam de suas concepções, abordagens e metodologias fundamentadas em suas experiências com o ensino de inglês para brasileiros.

Essa configuração se manteve até 2011, quando, após a oferta do curso de verão, foi selecionado um monitor, estudante do Programa de Pós-Graduação em Letras/Estudos Literários, para oferecer um curso de 40 horas ao longo do semestre. O curso não alcançou os objetivos esperados e atribui-se tal insucesso ao fato de que a formação do monitor era estritamente em Português Língua Materna (PLM) com foco no ensino de literatura. Além do mais, não obteve qualquer instrução inicial específica para atuar no novo contexto.

No segundo semestre de 2011, os rumos do PLE se modificavam sensivelmente com a contribuição de uma professora temporária da área de Línguas Estrangeiras Modernas que se responsabilizou pela oferta de um curso, não apenas aos alunos estadunidenses, mas também aos intercambistas de outros programas que se interessassem pela língua.

Nesse meio tempo, a busca por situar uma proposta de consolidação de política de cooperação internacional que sobrepusesse o desafio identificado pela DRI como um "desequilíbrio interno da inserção internacional"14, impulsionou a Diretoria a estabelecer objetivos para a instauração de uma área de ensino de PLE institucionalizada e organizada. O foco, portanto, era o de suprir o desafio da inserção internacional dos intercambistas em setores em que o conhecimento da língua portuguesa era essencial para atender ao requisito de

$14 \mathrm{O}$ “desequilíbrio interno da inserção interna cional" foi a ponta do em projeto desenvolvido em 2012/2013 com fomento do Edital FAPEMIG 14/2011, destinado ao Apoio à Criação ou Consolidação de Assessoria Internacional. No projeto, um dos objetivos da proposta se pautava em promover oferta de ensino adequado e contínuo da língua Portuguesa (cursos intensivos e cursos semestrais) para o maior número de estudantes estrangeiros na instituição. Este objetivo se apresentou como um dos fatores que permitiriam a correção entre o "desbalanceamento do intercâmbio acadêmico" local com seus parceiros internacionais e, por consequência, oportunizariam a participa ção de ma is estudantes da UFV em projetos de intercâ mbio e ações intercultura is. 
alguns convênios que exigiam como contrapartida a oferta de aulas de língua aos estudantes recém-chegados.

Com o fomento estadual do Edital 14/2011 da FAPEMIG ${ }^{15}$ direcionado à "Consolidação da Política de Cooperação Internacional da UFV", as atividades de ensino de PLE começaram a ser oferecidas em forma não só de cursos intensivos de verão, mas também como disciplinas optativas de 60 horas, pelos códigos LET 483 - Tópicos Especiais/ Português para Estrangeiros I e LET 484 - Tópicos Especiais IV/ Português para Estrangeiros II. As disciplinas eram oferecidas por professor selecionado pelo edital mencionado (coautor deste artigo) e alcançava alunos de diversas nacionalidades, dentre as quais tínhamos alunos estadunidenses, alemães, franceses, holandeses, italianos e, especialmente, latino-americanos de países como Peru, Costa Rica, Equador e Colômbia. Estes últimos, por serem de programas de mestrado e doutorado e terem suas estadias estendidas, eram os que se matriculavam para cursar a disciplina "Português para Estrangeiros II".

Além das atividades de ensino, os alunos participavam de viagens, atividades extraclasse e eventos locais por eles promovidos e assessorados por professores do departamento, tal como o "Caleidoscópio Cultural" (SILVA, 2019). Além disso, também foi oferecido um curso com foco no treinamento para resolução de tarefas aos moldes do Exame Celpe-Bras aos alunos hispanofalantes que se submeteriam ao exame na ocasião. $\mathrm{O}$ edital esteve em vigor por dezenove meses a partir de julho de 2012.

Após a conclusão do projeto supracitado, era urgente a solicitação de uma vaga específica para a contratação de um professor de PLE para o quadro efetivo da instituição. Por iniciativa da DRI em conjunto com o Departamento de Letras (DLA), realizou-se concurso para professor de PLE e isso conferiu um caráter institucional ao ensino de português como língua estrangeira, a partir do ano de 2013. A UFV então passou a fazer parte do painel das 10 universidades federais do país que obtiveram vaga de docente para a área de PLE (ALMEIDA; JÚDICE, 2016).

Em junho do mesmo, ano a vaga foi preenchida ${ }^{16}$ ao passo que no mês de agosto a instituição já contava com uma professora de PLE no quadro efetivo. Durante um ano (20132014), permaneceram as disciplinas LET 483 e LET 484, além da oferta de um curso intensivo de extensão em "Língua Portuguesa e Cultura Brasileira para Estrangeiros". Percebe-se, pois, a manutenção das mesmas ações desenvolvidas anteriormente. Contudo, no

${ }^{15}$ A Fundação de Amparo à Pesquisa do Estado de Minas Gerais, vinculada à Secretaria de Estado de Ciência, Tecnologia e Ensino do Governo Estadual, é a única agência de fomento ao desenvolvimento científico e tecnológico de Minas Gerais.

16 Processo 014088/2012/UFV, disponível no Diário Oficial da União de 9 de Abril de 2013.

Rev. EntreLínguas, Araraquara, v. 7, n. esp. 6, e021150, dez. $2021 . \quad$ e-ISSN: 2447-3529 
segundo semestre de 2014, com o pedido de exoneração da servidora então em exercício, foram selecionados dois monitores de graduação e um do programa de pós-graduação em letras para atuarem nas disciplinas de forma paliativa até a contratação da docente seguinte, que ocorreria no primeiro semestre de 2015. Com uma maior perspectiva de continuidade, consideramos ser este o período em que, de fato, o PLE/UFV se consolidou como área. A seguir, descreveremos as propostas e ações implementadas ao longo dos anos seguintes que se baseiam nos propósitos dos pilares fundamentais de ensino, pesquisa, extensão e, levando-os efetivamente a efeito como também, esforços particulares para a formação docente.

\section{Estágios de consolidação e seus pilares}

A consolidação do PLE/UFV é percebida, finalmente, a partir das ações departamentais implementadas nos últimos seis anos e se pautam nas modificações em termos de oferta de ensino, desenvolvimento de pesquisas e da efetivação de projetos de cunho extensionista. A partir de então, em 2015, a universidade se tornou posto aplicador do exame de proficiência em português como língua estrangeira (Celpe-Bras). Todas essas iniciativas corroboram o processo de internacionalização no plano interno da instituição. Esses pilares nos quais a área se solidificou, no entanto, são de difícil segmentação, visto que se comunicam e se complementam de várias formas, como será perceptível nas descrições abaixo. No entanto, somente a título de distinção de atividades, tentaremos cat egorizá-las.

\section{O Pilar Ensino}

A partir do primeiro semestre de 2015, os cursos de PLE foram ofertados como disciplinas semestrais de $60 \mathrm{~h}$ e possuíam as mesmas configurações praticadas desde 2013. Essa configuração, porém, sofreu modificações no ano seguinte, com a criação de disciplinas que compreenderam as necessidades específicas para atender grupos particulares de estudantes, sob a iniciativa de um dos autores deste artigo. Inicialmente, as turmas eram homogeneizadas e não se levavam em conta as diferenças no nível das dificuldades apresentadas por alunos falantes de línguas tipologicamente próximas (português-espanhol) e aqueles falantes de línguas distantes, como os asiáticos, por exemplo, principalmente no que diz respeito à pronúncia, à compreensão e ao vocabulário, conforme estudos em andamento na 
$U_{F V}{ }^{17}$. Outra questão, que foi colocada em discussão e serviu como orientadora para as mudanças realizadas, levava em consideração os propósitos de aprendizagem da língua por estudantes que estariam na universidade somente para programas de mobilidade internacional ${ }^{18}$ em nível de graduação e, também, focalizando os propósitos e necessidades de alunos vinculados a programas de pós-graduação. Com isso, foram criadas as disciplinas LET 204 (que atende estudantes de mobilidade acadêmica da graduação) e a LET 604 (para alunos de pós-graduação).

Dessa forma, o ensino da língua para os estudantes em mobilidade internacional tem uma configuração exclusiva que prioriza a compreensão e comunicação básicas. Há de se prover uma metodologia distinta e contextualizada, pois estão imersos na língua e na cultura, mas por um tempo muito curto, geralmente apenas por um semestre. Contudo, para os estudantes da pós-graduação, que permanecem entre 2 a 5 anos na universidade, além da necessidade da compreensão e comunicação, precisam desenvolver habilidades de leitura e produção de textos. Cada disciplina é dividida em uma parte teórica, que prioriza os aspectos formais da língua, nas modalidades oral e escrita, e em outra parte prática, em que se enfatiza a conversação e compreensão oral. As atividades práticas privilegiam os aspectos audiovisuais como músicas, vídeos, filmes brasileiros e, ainda, o desenvolvimento da oralidade, através de apresentações orais, realizadas pelos estudantes ao final de cada semestre. No caso dos alunos de pós-graduação, o foco é na leitura de artigos, na interpretação de textos, na produção oral e escrita e na preparação para a realização do exame de proficiência em português como língua estrangeira, com o objetivo de obterem o Certificado de Proficiência em Língua Portuguesa para Estrangeiros (Celpe-Bras).

\section{O Pilar Extensão}

Apesar de alguns cursos específicos de extensão com o foco em PLE já tivessem sido realizados no âmbito institucional, foi somente a partir de 2015 que a área se inseriu oficialmente nas atividades extensionistas da universidade. Tal inserção foi possibilitada através da criação do projeto de extensão nomeado "Curso de Extensão em Língua Portuguesa para Estrangeiros" (CELIPE) ${ }^{19}$, idealizado e coordenado pela Profa. Dra. Idalena Oliveira

${ }^{17}$ A pesquisa de iniciação científica intitulada "Identificando as estratégias da expressão da temporalidade em PLE em aprendizes iniciantes”, orientada pela Profa. Dra. Aparecida Araújo, aponta para este fenômeno.

18 Mobilidade internacional é um programa para receber e/ou enviar estudantes de/para vários países para difundir a internaciona lização e promover oportunidades de intercâmbio no exterior, socializando experiência s e conhecimentos entre estudantes estrangeiros.

${ }^{19}$ Disponível em: https://www.celipe.ufv.br/. Acesso em: 10 jul. 2021. 
Chaves e desenvolvido por professores colaboradores do Departamento de Letras. O projeto, em andamento por seis anos, visa oferecer cursos de português para atender aos familiares dos estudantes (filhos e cônjuges), pois estes não podem cursar as disciplinas regulares visto que não se encontram oficialmente vinculados à universidade. Além de cursos de PLE, também são oferecidas aulas de português como língua adicional para surdos e, ainda, português como língua estrangeira para crianças. O projeto também objetiva, para além das atividades de ensino, contribuir para a formação e prática de ensino de alunos do curso de licenciatura em Letras, além de funcionar como lócus fértil para o desenvolvimento de pesquisas em português como Língua Estrangeira/Adicional na instituição.

Outro projeto desenvolvid o ao longo do processo de solidificação da área, iniciado em 2016, focaliza o ensino de Português como Língua de Herança (PLH), para o qual foi produzido um portal educativo ${ }^{20}$ para que crianças brasileiras, residentes no exterior, e os filhos dos estudantes estrangeiros matriculados em escolas regulares da cidade, pudessem aprender/desenvolver suas habilidades em língua portuguesa com atividades linguísticas e musicais.

Por fim, citamos também o Projeto Procultura, cujo foco está no letramento literário e se destina a desenvolver as habilidades de leitura e oralidade dos alunos estrangeiros da pósgraduação, falantes de espanhol, realizando intervenções de leitura com estudantes do ensino fundamental nas escolas públicas de Viçosa, em parceria com o Curso de Licenciatura em Espanhol do Departamento de Letras da UFV.

\section{O pilar Pesquisa}

Com relação à produção científica na área de PLE, a universidade, através do Departamento de Letras, tem promovido o desenvolvimento de projetos de pesquisa que vão desde trabalhos de iniciação científica (IC) a dissertações de mestrado. Tais estudos englobam temas como cultura, comunicação intercultural, concepções e crenças de alunos, análise de necessidades, avaliação, uso de tecnologias, ensino de português como língua de herança, dentre outros, conforme descrito no quadro abaixo: 
Tabela 2 - Pesquisas concluídas na área de PLE na UFV

\begin{tabular}{|c|c|c|}
\hline Ano & Autor. Título / (Tipo de Produção) & Orientador(a) \\
\hline 2011 & $\begin{array}{l}\text { Glauber Heitor Sampaio. Português como Língua Estrangeira: um estudo das } \\
\text { relações entre experiências, crenças e motivações / (Monografia) }\end{array}$ & $\begin{array}{l}\text { Ana Maria } \\
\text { Ferreira } \\
\text { Barcelos }\end{array}$ \\
\hline 2015 & $\begin{array}{l}\text { Glauber Heitor Sampaio. A negociação de categorias de pertencimento em } \\
\text { interação intercultural na sala de aula de português como Língua Estrangeira / } \\
\text { (Dissertacão de Mestrado) }\end{array}$ & $\begin{array}{l}\text { Wania } \\
\text { Terezinha } \\
\text { Ladeira }\end{array}$ \\
\hline 2016 & $\begin{array}{l}\text { Marina de Paulo Nascimento. Crenças de alunos hispano-falantes sobre a } \\
\text { proficiência em português brasileiro como língua estrangeira em um curso } \\
\text { preparatório para o exame CELPE-Bras / (TCC) }\end{array}$ & $\begin{array}{l}\text { Glauber Heitor } \\
\text { Sampaio }\end{array}$ \\
\hline 2016 & $\begin{array}{l}\text { Tamires de Castro Ferreira. O perfil dos estudantes estrangeiros na UFV: estudo } \\
\text { introdutório / (IC) }\end{array}$ & $\begin{array}{l}\text { Idalena Oliveira } \\
\text { Chaves }\end{array}$ \\
\hline 2017 & $\begin{array}{l}\text { Mateus Lopes de Souza. Perfil dos estudantes estrangeiros na UFV: criação de } \\
\text { um curso-on-line intercultural de português para estrangeiros / (IC) }\end{array}$ & $\begin{array}{l}\text { Idalena Oliveira } \\
\text { Chaves }\end{array}$ \\
\hline 2017 & $\begin{array}{l}\text { geira: reflexões } \\
\text { C) }\end{array}$ & $\begin{array}{l}\text { Glauber Heitor } \\
\text { Sampaio }\end{array}$ \\
\hline 2018 & $\begin{array}{l}\text { Matheus Figueira. Análise das Necessidades de Alunos Falantes de Línguas } \\
\text { Germânicas / (TCC) }\end{array}$ & $\begin{array}{l}\text { Ida lena Oliveira } \\
\text { Chaves }\end{array}$ \\
\hline 2018 & $\begin{array}{l}\text { Tamires de Castro Ferreira. Perfil dos estudantes estrangeiros na UFV: estudo } \\
\text { introdutório para a elaboração de um portal educativo para o ensino de } \\
\text { português / (TCC) }\end{array}$ & $\begin{array}{l}\text { Idalena Oliveira } \\
\text { Chaves }\end{array}$ \\
\hline 2018 & $\begin{array}{l}\text { Mateus Lopes de Souza. Análise das Necessidades de Alunos Falantes de } \\
\text { Línguas Germânicas / (TCC) }\end{array}$ & $\begin{array}{l}\text { Ida } \\
\text { Cha }\end{array}$ \\
\hline 2018 & $\begin{array}{l}\text { Matheus Pereira Figueira de Oliveira. Análise da Interferência da língua materna } \\
\text { na escrita ortográfica de falantes de espanhol na prova escrita do exame Celpe- } \\
\text { bras / (TCC) }\end{array}$ & $\begin{array}{l}\text { Ida lena Oliveira } \\
\text { Chaves }\end{array}$ \\
\hline 2019 & $\begin{array}{l}\text { Ramone Maria da Costa e Silva. A música popular brasileira (MPB) como } \\
\text { suporte para trabalhar a interculturalidade em aulas de português para } \\
\text { Estrangeiros (PLE)/(TCC) }\end{array}$ & $\begin{array}{l}\text { Idalena Oliveira } \\
\text { Chaves }\end{array}$ \\
\hline 2019 & $\begin{array}{l}\text { Pa loma de Paula Fagundes. A volta ao mundo em várias histórias: uma proposta } \\
\text { de Letramento Literário para estudantes estrangeiros / (TCC) }\end{array}$ & $\begin{array}{l}\text { Idalena Oliveira } \\
\text { Chaves }\end{array}$ \\
\hline 2019 & $\begin{array}{l}\text { Erica Fernandes Borges. Da língua de origem à língua de herança: a } \\
\text { manutenção do espanhol por hispanofalantes na zona da mata mineira / } \\
\text { (Dissertação de Mestrado) }\end{array}$ & $\begin{array}{l}\text { Idalena Oliveira } \\
\text { Chaves }\end{array}$ \\
\hline 2020 & $\begin{array}{l}\text { Caroline Campos Fraga. O uso de mídias digitais para o desenvolvimento da } \\
\text { oralidade em Português para Estrangeiros / (IC) }\end{array}$ & $\begin{array}{l}\text { Ida lena Oliveira } \\
\text { Chaves }\end{array}$ \\
\hline 2020 & $\begin{array}{l}\text { Flávia Rodrigues de Souza. Língua, cultura e migração: desenvolvimento } \\
\text { linguístico e cultural de crianças de famílias migrantes internacionais em } \\
\text { Viçosa, Minas Gerais / (Dissertação de Mestrado) }\end{array}$ & $\begin{array}{l}\text { Michelle Nave } \\
\text { Valadão }\end{array}$ \\
\hline 2021 & $\begin{array}{l}\text { Mariana Alves Abrantes. Português todo dia: Uso da plataforma YouTube para } \\
\text { o ensino de Português como Língua Estrangeira / (TCC) }\end{array}$ & $\begin{array}{l}\text { Idalena Oli } \\
\text { Chaves }\end{array}$ \\
\hline
\end{tabular}

Fonte: Acervo dos autores

Com base nos trabalhos enumerados, a produção crescente sinaliza que o desenvolvimento da área tem se efetivado de forma intensa e colaborado para as discussões em PLE. Em termos de pesquisas executadas a partir de 2015, destacam-se, além daquelas elencadas acima, a criação do grupo de pesquisa "Gruppelhe - Grupo de pesquisa em Português Língua Estrangeira e Línguas de Herança" (CNPQ), que busca contribuir com estudos e pesquisas sobre a temática específica no Brasil e no exterior. Além deste, está em desenvolvimento o projeto institucional intitulado "A internacionalização da língua portuguesa na UFV: criação de portal pedagógico para ensino e aprendizagem de Português 
do Brasil como Língua Estrangeira e Língua de Herança (PBLH)”, com foco na produção de material na modalidade de Educação a Distância para estrangeiros e crianças brasileiras residentes no exterior.

Além das ações já mencionadas, destaca-se também a pesquisa designada como o "Perfil dos estudantes estrangeiros na UFV: estudo introdutório para a elaboração de um portal educativo para o ensino de português" que, como o próprio título indica, busca traçar o perfil dos estudantes estrangeiros na UFV, a partir do qual tem orientado a criação de um portal educativo para ensino PLE na instituição, e b) o projeto de ensino "A produção de curso on-line para o ensino e a aprendizagem de Português do Brasil para estrangeiros residentes no exterior", que se desenvolve na perspectiva de compreender as demandas linguísticas de aprendizagem do português por alunos em fase de preparação pré-intercâmbio e já apresenta resultados na efetivação do canal "Português Todo Dia", disponível no Youtube21, o que colabora também para a aprendizagem de PLE de forma autônoma.

Todos os pilares delineados até aqui se apoiam e confluem, sobremaneira, para a efetivação do último pilar a ser descrito, a formação de professores.

\section{O Pilar Formação de Professores e seus desafios}

O DLA/UFV forma professores em quatro habilitações distintas: Português, Inglês, Francês, Espanhol e suas respectivas literaturas. Apesar de não haver uma habilitação voltada para a formação de professores para o ensino de PLE, foi criada em 2016 a disciplina denominada "Ensino de português como língua estrangeira" (LET 304), para suprir essa demanda. A disciplina, ofertada no primeiro semestre de cada ano, tem contribuído para oportunizar a criação de uma equipe interessada em desenvolver projetos diversos de ensino, pesquisa e extensão.

Até os dias atuais, ainda encontramos um panorama comum em que leigos são convidados para oferecer cursos de PLE. Professores de outras línguas ou mesmo de Português Língua Materna ministram esses cursos regularmente. No exterior, inclusive, ainda se presencia brasileiros incumbidos por ensinar sem alguma formação, apenas pelo fato de serem nativos. Ensinar a própria língua materna para um estrangeiro difere de ensiná-la como língua materna para o nativo. Então, como é ser professor de português para estrangeiros? O

${ }^{21}$ Disponível em: https://www.youtube.com/channel/UC2feXRNHa7Wxj4DLEYgAr2g. Acesso em: 20 maio 2021. 
que difere o ensino do português como língua materna do ensino de português como língua estrangeira?

De acordo com Nóbrega (2010), as diferenças já começam nas situações de aquisição e aprendizado. Para a autora, a aquisição da língua materna acontece naturalmente e mais rápido, movida pelo desejo de se comunicar, enquanto uma língua estrangeira, aprendida em situação formal e por uma necessidade específica, acaba sendo menos natural, levando o aprendiz a inferir regras para a língua alvo a partir da comparação de estruturas da sua língua materna. Outro ponto divergente diz respeito ao repertório cultural do aprendiz tendo em vista que "na LM estamos literalmente em casa. Inseridos na cultura e na sutileza de seus imperativos, somos conhecedores natos do que se aprova e do que se rechaça" (NOBREGA, 2010, p.7), o que faz com que o aprendiz da LE, de certa forma, compare estes aspectos e apresente problemas para se adaptar à nova cultura ou até rejeitá-la. Enfrentar as mudanças e as dificuldades de adaptação a uma nova língua, um novo trabalho, um estilo de vida e à própria cultura não é simples. É isso que mobiliza uma formação específica, com uma produção de materiais didáticos próprios para atender aos imperativos do estudante estrangeiro, principalmente ao envolver relações de interação interculturais.

A formação de professores de português na modalidade de língua não materna, embora crescente, ainda é incipiente no país. A Universidade Federal da Bahia (UFBA) e a Universidade de Brasília (UNB) são pioneiras nesta formação. Recentemente, foram criadas duas universidades com esse perfil internacional. A primeira, a Universidade Federal de Integração Latino-americana (UNILA), visa formar licenciados em Letras - Espanhol e Português como Línguas Estrangeiras, cuja proposta focaliza na formação do profissional para atuar tanto no ensino básico quanto em cursos livres, em instituições de ensino do Brasil e dos demais países da América Latina. A segunda, Universidade da Integração Internacional da Lusofonia Afro-brasileira (UNILAB), instituída em 2010, no Ceará, propõe

[...] ministrar ensino superior, desenvolver pesquisas nas diversas áreas de conhecimento e promover a extensão universitária, tendo como missão institucional específica formar recursos humanos para contribuir com a integração entre o Brasil e os demais países membros da Comunidade dos Países de Língua Portuguesa - CPLP, especialmente os países africanos, bem como promover o desenvolvimento regional e o intercâmbio cultural, científico e educacional (UNILAB, 2010[Web]). ${ }^{22}$

${ }^{22}$ Sobre a criação da Unilab. Disponível em: http://www.planalto.gov.br/ccivil_03/_Ato2007- 
Adicionalmente, entre 2013 e 2015, foram criados cursos de "Licenciatura em Letras: Libras/Língua Portuguesa como Segunda Língua” na Universidade Federal do Acre (UFAC) e a habilitação em "Português como Segunda Língua e Língua Estrangeira" na Universidade Estadual de Campinas (UNICAMP). Desde 2006, eram ofertadas as disciplinas Ensino do Português Segunda Língua/Língua Estrangeira e Pesquisa em Português Segunda Língua/Língua Estrangeira, ministradas no Instituto de Estudos de Linguagem (IELUnicamp), já prenunciando a possibilidade da criação da licenciatura específica, possível a partir de 2015, como uma alternativa aos estudantes de Letras desta universidade para ampliarem a sua formação. Há, ainda, o Instituto Federal de Educação, Ciência e Tecnologia de Goiás, em Goiânia (IFG) ${ }^{23}$ que, no curso de formação de professores de Letras, apresenta diferencial com disciplinas voltadas para o ensino de português para estrangeiros, assim como na UFV, segundo já evidenciado.

Algumas instituições brasileiras oferecem formação específica para a atuação na referida área em cursos de pós-graduação Lato Sensu, a exemplo da Universidade Federal Fluminense (UFF) e do curso de Formação de Professores de Português para Estrangeiros do programa de Educação continuada da PUC-Rio. Em muitas das universidades federais, já são ofertadas disciplinas nos cursos de graduação e pós-graduação para formação de professores, como constatado em Marques e Schoffen. No entanto, como afirmam as autoras:

[...] é fundamental que o governo e as universidades reconheçam a importância cada vez maior da área, abram mais espaço para docentes especializados em PLA e invistam na inclusão de disciplinas com foco na formação de professores de PLA nas grades curriculares dos cursos de Letras, além de incentivarem a abertura de mais cursos de licenciatura em PLA (MARQUES; SCHOFFEN, 2020, p. 409).

Mesmo com essas possibilidades sendo promovidas, o professor de PLE ainda enfrenta alguns desafios, como a pouca disponibilização de materiais didáticos que os auxiliem nos diferentes contextos de atuação, bem como pesquisas que discutam o próprio fazer didático neste cenário tão específico e marcado por necessidades, muitas vezes, ímpares. Ainda que haja uma quantidade considerável de livros didáticos no mercado (conforme elencados no site do Iel-Unicamp ${ }^{24}$ ), ainda é difícil adequar o material às situações de aprendizagem contextuais, locais e que atendam as realidades de certos grupos. Embora os livros contemplem situações sociocomunicativas vivenciadas no Brasil, em geral tendem a representar a região geográfica de origem destes autores, imprimindo aos diálogos e textos

${ }^{23}$ Disponível em: https://cursos.ifg.edu.br/info/lic/lic-letras/CP-GOIANIA. Acesso em: 20 maio 2019.

${ }^{24}$ Disponível em: https://www2.iel.unicamp.br/matilde/materia is-didaticos/. Acesso em: 20 ma io 2019. 
marcas discursivas distintas que, nem sempre, descrevem os usos da língua falada em certos locais e seus regionalismos, além de metodologias, abordagens e necessidades específicas dos grupos de atuação docente. Isso demanda uma adaptação e um processo de formação de professores que saibam lidar e apresentar de maneira refletiva e informada as variantes que, por razões óbvias, não podem ser contempladas em sua totalidade em um LD. Desta forma, tal ad equação torna-se um dos desafios para o professor em formação ou mesmo em serviço.

Outro grande desafio para o professor é mobilizar o conhecimento dos alunos que vivem em contexto de imersão linguística e cultural e transitam entre o ambiente universitário e a comunidade local, como ocorre na cidade de Viçosa, Minas Gerais. O que o estrangeiro aprende com a comunidade transforma-se conteúdo da sala de aula. Para trabalhar com estrangeiros neste contexto, é fundamental que o professor valorize a própria cultura e respeite a cultura do outro, desafio este que está diretamente atrelado ao trabalho árduo de formação e sensibilidade intercultural do docente. Para Leffa, a formação de professores é uma "tarefa extremamente complexa, difícil de ser completada num curso de graduação, pois envolve aspectos linguísticos e políticos da natureza humana, que não se adquire em 3,4 anos" (LEFFA, 2008, p. 335). Concordamos com o autor em relação a essa imensa dificuldade de, em um curso de graduação, formar professores de línguas estrangeiras com habilidades para lidar com os aspectos linguísticos do idioma, comprometidos com o ensino e, ainda, competentes na gestão da interculturalidade e das tecnologias que se tornam cada vez mais lugar-comum na atuação do professor. Sabe-se que nos cursos de Letras regulares, com as suas especificidades, não é tarefa fácil arcar com o compromisso de preparar docentes que sejam reflexivos e desempenhem seus papéis de maneira informada para essa nova demanda, o que aponta para ampliação do tempo da formação, apresentando a opção de expandir a licenciatura para português como segunda língua, como foi feito na Unicamp em $2015^{25}$, como uma possível solução para este desafio.

Nesse sentido, torna-se imperativo se debater e colocar em pauta a formação de professores para a atualidade que, cada vez mais, torna-se complexa e móvel, tendo em vista a procura de professores para atuarem especificamente nesta área, a exigência da formação e a falta dela para contemplar os contextos de atuação de ensino plurais para a aprendizagem do português como língua estrangeira. Para formar professores de português para estrangeiros é preciso, portanto, desenvolver neles a sensibilidade cultural, promover oportunidades de reflexão sobre sua alteridade, compreendendo-a sem julgamentos e comparações 
etnocêntricas (NIEDERAUER, 2010), além de explicitar o ensino como tarefa complexa que demanda cada vez mais novas propostas que incluem o uso de tecnologias e levem em consideração as necessidades contextuais (e culturais) dos aprendizes. É necessário, ainda, conhecer a língua em foco para responder questionamentos linguísticos e socioculturais que são trazidos para o ambiente da sala de aula, oriundos da comunidade de fala a que o estrangeiro passa a interagir. Conforme o que até agora foi explicitado, acreditamos que os pilares apresentados têm contribuído não só para a consolidação da área no contexto descrito, mas também para uma formação teórico-prática que se converterá em melhorias no processo de profissionalização do docente no sentido de minimizar os desafios que encontrarão na sua prática profissional futura. Para tanto, além dos pilares, reconhecemos a importância de ações políticas que possam confluir e dinamizar a formação docente, conforme pontuaremos a seguir.

\section{Ações políticas de formação na UFV e seus próximos passos}

Todas as questões pontuadas nas seções anteriores estiveram presentes nas discussões realizadas em evento sobre $\mathrm{o}$ ensino e a pesquisa em Português como Língua Estrangeira/Língua Adicional $^{26}$ realizado na UFV. Inferiu-se, então, a necessidade de uma licenciatura em $\operatorname{PLE}^{27}$.

A ideia era propor um curso de formação mais específico, com seleção de conteúdo que pudesse contemplar os aspectos linguísticos, a cultura, a literatura, a história e as questões da sociedade, além de abraçarem metodologias e as tecnologias que podem ser direcionadas ao aluno que fala uma outra língua que não o português. As discussões, em andamento, vêm ganhando forma com a instauração de políticas linguísticas na universidade. O Departamento de Letras apresentou, em 2018, uma proposta para a redação de uma resolução para a Política Linguística da UFV. O conselho de ensino, pesquisa e extensão aprovou o documento que foi assinado pela reitoria constando no seu art. $4^{\circ}$, parágrafo $V$, “[...] favorecer ações de ensino e aprendizagem de diferentes línguas na UFV, incluindo a Língua Brasileira de Sinais (Libras) e o maior acesso ao português como língua adicional"28.

${ }^{26}$ Disponível em: http://ampplie.com.br/evento/i-emepple-pla. Acesso em: 20 maio 2019.

${ }^{27}$ Ressalta-se a situação dos surdos, que numa perspectiva bilinguista, tem o português como segunda língua. Não cabe no escopo desse artigo a dentrar nesta discussão, no entanto, como faz parte da resolução da política linguística da universidade é imperativo mencionar essa demanda.

${ }^{28}$ Resolução 09/2018. Disponível em: http://www.soc.ufv.br/wp-content/uploads/09-18.pdf. Acesso em: 15 jul. 2021. 
Nessa perspectiva, uma formação em português como "língua adicional" seria mais adequada, tendo em vista que, de acordo com Schlatter e Garcez (2009), o termo "Língua Adicional" (LA) é mais abrangente, visto que nas modalidades oral e/ou escrita o "adicionar" mais uma língua no repertório linguístico do usuário torna possível a sua inserção nas práticas sociais das quais ele já participa. Dessa forma, contempla-se o ensino de português para surdos e falantes de outras línguas.

\section{Considerações finais}

Buscou-se, neste texto, a exposição de alguns pontos relacionados ao processo de internacionalização das universidades e a situação da área de PLE na Universidade Federal de Viçosa, culminando no anúncio sobre a aprovação da resolução de política linguística aprovada na universidade em questão. Isso se configura como um passo importante para guiarmos as ações adequadas para os professores em formação na contemporaneidade.

Especificamente, traçamos o percurso da área de ensino e aprendizagem do Português como Língua Estrangeira na Universidade Federal de Viçosa, apresentando as iniciativas e políticas de formação docente em PLE que vêm sendo discutidas e implementadas no Departamento de Letras sob os pilares nos quais este percurso tem se alicerçado. Por ser uma universidade essencialmente internacional, a UFV tem oferecido um espaço propício para a implementação de pesquisas e de ações políticas voltadas a formação de futuros professores, o que a torna uma fomentadora de ações formativas no âmbito do ensino-aprendizagem que tem aproximado seus estudantes de uma perspectiva que lhes possibilite lidar com a heterogeneidade cultural ou, de acordo com Welsch (1999), da transculturalidade. Essa definição, que emerge nos estudos de línguas, é bastante relevante para defrontar com o contexto que estamos vivenciando em relação aos estudantes estrangeiros que entram nas nossas universidades e os imigrantes que entram no nosso país, tendo como força propulsora a identificação de necessidades, o uso de tecnologias e a formação docente para o reconhecimento e efetivação de tais pontos de convergência. Tudo isso favorecerá uma formação mais sólida em termos teórico-práticos que venham somar no processo de ensinoaprendizagem de PLE no Brasil e no exterior.

Assim sendo, temos vislumbrado a adoção de práticas de ensino, pesquisa e extensão que, dentro de uma abordagem múltipla e transcultural pode (e deve) ser usada para a elaboração de um currículo adequado às necessidades da formação docente que, 
potencialmente, poderão ampliar as perspectivas dos professores para atuarem com a diversidade em diferentes salas de aula e contextos de ensino de português para estrangeiros.

\section{REFERÊNCIAS}

ALMEIDA, P.; JÚDICE, N. Do novo mundo ao mundo novo: o ensino de português a estrangeiros no brasil. In: ORTIZ A. M. L.; GONÇALVES, L. O Mundo do Português e o Português no Mundo a fora: especificidades, implicações e ações. Campinas, SP: Pontes Editores, 2016. p. 265-292

BAÊTA, O. V. Estratégias como práticas sociodiscursivas em uma universidade pública: uma abordagem crítica. 2016. Tese (Doutorado) - Universidade Federal de Lavras, Lavras, 2016.

BASTOS, C. C. B. C. O Processo de Bolonha no espaço europeu e a reforma Universitária Brasileira. Educação Temática Digital, Brasília, DF, p. 95-106, 18 jan. 2008.

BERTRAND, G. Le grand tour revisite: Pour une archéologie du tourisme, le voyage des Français en Italie, milieu XVIIIe - début XIXe siècle. Publications de l'École française de Rome: Rome. 2013.

BLOG DO IILPE. Português, a língua mais falada do hemisfério sul. 2019. Disponível em: https://illp.word press.com/2019/03/08/portugues-a-lingua-mais-falada-do-hemisferio-sul/. Acesso em: 08 mar. 2021.

FILHO, J. C. P. A O Ensino de Português para Estrangeiros nas Universidades Brasileiras. In: FILHO, J. C. P. A; LOMBELLO, L. Identidade e Caminhos no Ensino de Português para Estrangeiros. Campinas, SP: Pontes, 1992. p. 11-16.

FULQUET, G. A. EI Proyecto Educativo para el MERCOSUR y los Debates en torno a la Internacionalización de la Educación Superior. Buenos Aires: Universidad del Salvador (USAL), 2006.

LEFFA, V. J. Aspectos políticos da formação do professor de línguas estrangeiras. In: LEFFA, V. J. (org.). O professor de línguas estrangeiras: construindo a profissão. Pelotas, 2001. v. 1, p. 333-335.

MARQUES, A. A. M.; SCHOFFEN J. R. Português como Língua Adicional nas Universidades Federais Brasileiras: um perfil da área. Letras de hoje, Porto Alegre, v. 55, n. 4, p. 394-411, out./dez. 2020

MOROSINI, M. C. Estado do conhecimento sobre internacionalização da educação superior: conceitos e práticas. Educar em Revista, n. 28, p. 107-124, 2006.

NIEDERAUER, M.E. F. Estranhamentos culturais em sala de aula de português para estrangeiros. In: SANTOS, P.; ORTIZ, M. L. A. (org.). Língua e cultura no contexto de português língua estrangeira. Campinas, SP: Pontes Editores, 2010. p. 101-121. 
NÓBREGA, M. H. Ensino de português para nativos e estrangeiros: na prática, a teoria é outra. Revista Linha D'água, São Paulo, n. 23, 2010.

RIBEIRO, M. G. M. A USAID e o ensino agronômico brasileiro: o caso da Universidade rural do Estado de Minas Gerais (UREMG). Bol. Mus. Para. Emílio Goeldi, v. 4, n. 3, p. 453-463, 2009.

RIBEIRO, M. G. M. Caubóis e caipiras. Os land-grant colleges e a Escola Superior de Agricultura de Viçosa. História da Educação,v. 10, n. 19, p. 105-119, 2006.

SANTOS, L. Ensino e aprendizagem de português para estrangeiros in-tandem em contexto virtual: primeiros passos de um projeto franco-brasileiro. In: SANTOS, L.; SIMÕES, D.

Ensino de português e suas tecnologias: coletânea de textos apresentados no I SIMELP. Rio de Janeiro: Dialogarts. 2009. p. 147-160.

SILVA, R. M. O. Caleidoscópio Cultural: de evento departamental a projeto intercampi.

Revista ponto de vista, v. 8, n. 1, p. 120, 2019. Disponível em:

https://periodicos.ufv.br/RPV/article/view/9209. Acesso em: 07 jan. 2021.

UNILAB. Universidade da Integração Internacional da Lusofonia Afro-brasileira. Unilab Institucional. 2010. Disponível em: https://unilab.edu.br/institucional-

2/\#: :text=De\%20acordo\%20com\%20a\%20legisla\%C3\%A7\%C3\%A3o,os\%20demais\%20pa $\%$ C3\%ADses $\% 20$ membros\%20da. Acesso em: 10 out. 2018.

WELSCH, W. Transculturality - the puzzling form of cultures today. In: FEATHERSTONE, M.; LASH, S. (org.). Spaces of Culture: City, Nation, World. London: Sage. 1999. p. 194213.

\section{Como referenciar este artigo}

CHAVES, I. O.; HEITOR-SAMPAIO, G. Percursos e desafios ao longo do processo de consolidação do português para estrangeiros na UFV. Rev. EntreLínguas, Araraquara, v. 7, n. esp. 6, e021150, dez. 2021. e-ISSN: 2447-3529. DOI: https://doi.org/10.29051/el.v7iesp.6.15444

Submetido em: $31 / 08 / 2021$

Revisões requeridas em: 15/10/2021

Aprovado em: $30 / 11 / 2021$

Publicado em: 28/12/2021 